\title{
EARLY OUTCOME OF CORONARY ARTERY BYPASS GRAFTING WITH OR WITHOUT MITRAL VALVE INTERVENTION IN PATIENTS WITH MODERATE ISCHEMIC MITRAL REGURGITATION
}

\author{
Walaa Ahmed Saber, Mohamed Mohamed Elfeky, Osama Abbas Abd Elhameed, \\ Mohammed Nabil Abd Algwad and Elsayed Mansour Elsayed Herry*
}

\begin{abstract}
Department of Cardiothoracic Surgery, Faculty of Medicine Ain Shams University, Cairo, Egypt.
\end{abstract}

\section{Corresponding author}

Elsayed Mansour Elsayed Herry

Mobile: (+2) 01007854962

E.mail:

doctor7erry@gmail.com

Received: 9/6/2021

Accepted: 1/7/2021

\section{Online ISSN: 2735-3540}

\begin{abstract}
Background: Ischemic mitral regurgitation is a common clinical problem of coronary artery disease, developing acutely after myocardial infarction in up to $19 \%$ of patients. It may be chronic condition being found approximately in $3 \%$ of patients undergoing coronary angiography, or may less commonly occur as a regional episode of ischemia.
\end{abstract}

Aim of the Work: We reviewed outcomes of the most problematic subgroup of patients in terms of surgical approach-patients with moderate IMR. We evaluated the effectiveness of CABG with or without repair $M V r$ with regard to changes in functional class, postoperative MR, LV function and short term survival benefit.

Patients and Methods: Between July 2017 and June 2020, a cohort of sixty patients with ischemic heart disease associated with moderate chronic ischemic mitral regurgitation. The study was carried out in the department of cardiac surgery and other multicenters after obtaining the approval of the local ethical committee and a fully-informed written consent from each patient.

Results: After our study evaluation, we found that patients who were offered the combined approach of $C A B G$ with repair, showed more improvement as to clinical and echocardiographic parameters, compared to those who were offered the CABG alone procedure. We also found that a worse preoperative $L V$ function is the reason that leads to the persistence or progression of the IMR pathology towards severer grades in the $C A B G$ only patients.

Conclusion: The efficacy of adding MVR to CABG is well demonstrated by the improvement of NYHA functional class and LVEF over the early (3 months) \& late (6 months) postoperative follow-up periods.

Keywords: Coronary artery disease, Coronary artery bypass grafting, repair $M V r$

\section{INTRODUCTION:}

Coronary artery disease (CAD) can lead to ischemic mitral regurgitation (IMR) due to myocardial ischemia or infarction in the absence of any intrinsic organic disease of the mitral valve $\mathrm{e}^{(\mathbf{1})}$.
Uncorrected chronic mitral regurgitation (MR) is associated with a poor prognosis in patients after coronary revascularization by means of coronary artery bypass grafting (CABG) or percutaneous transluminal coronary angioplasty ${ }^{(2 \& 3)}$. 


\section{Walaa Ahmed Saber, et al.,}

Many investigators have evaluated the pathogenesis of ischemic MR and have been able to show the crucial role of changes in the geometry of the left ventricle (LV) and papillary muscle due to the myocardial scarring that results in annular dilation and leaflet tethering ${ }^{(4,5)}$.

Because of higher morbidity and operative mortality rates associated with combined revascularization and mitral valve surgery ${ }^{(6)}$, some surgeons have advocated revascularization alone ${ }^{(7)}$, while others have recommended concomitant mitral valve surgery in order to optimize patients' cardiac function and long-term prognosis ${ }^{(\mathbf{8})}$.

Although most surgeons would agree that mild MR can be treated by CABG alone and that severe MR should be corrected at the time of $\mathrm{CABG}$, the optimal approach toward the management of moderate ischemic MR remains controversial ${ }^{(\mathbf{1})}$.

It has been shown that patients with moderate MR have lower survival rates after undergoing $\mathrm{CABG}$ alone than do patients who have no $\mathrm{MR}$ or mild $\mathrm{MR}^{(\mathbf{9})}$, and that CABG alone leaves many patients with substantial residual $\mathrm{MR}^{(\mathbf{8})}$.

Although many studies have been undertaken in order to define the risk factors for high mortality rates and the appropriate approach, there is no clear consensus regarding the optimal treatment of these highrisk ischemic patients with moderate $\mathrm{IMR}^{(\mathbf{1})}$.

\section{AIM OF THE WORK:}

In this study, we reviewed outcomes of the most problematic subgroup of patients in terms of surgical approach-patients with moderate IMR. We evaluated the effectiveness of CABG with or without mitral valve intervention (repair $\mathrm{MVr}$ ) with regard to changes in functional class, postoperative MR, $\mathrm{LV}$ function and short term survival benefit.

\section{PATIENTS AND METHODS:}

This study is designed in a randomized controlled trial to enroll 60 patients, recruited from multicenters, referred for CABG and have moderate ischemic mitral regurgitation measured by echocardiography alone. The study was done at the Cardiac Surgery Department, Naser institute hospital and the Cardiac Surgery Department,faculty of medicine,Ain Shams university from July 2017 to June 2020.

Inclusion criteria: Elective, primary multiple on pump coronary artery bypass grafting with moderate ischemic functional mitral regurgitation.

Exclusion criteria: severe LV dysfunction (ejection fraction <30\%), structural abnormalities of the mitral valve (including papillary muscle rupture), significant aortic valve disease, previous or active endocarditis, New York Heart Association (NYHA) class IV symptoms, unstable angina, acute pulmonary edema or cardiogenic shock, significant comorbidities (severe renal impairment, liver impairment, chronic obstructive airways disease) or other associated conditions that significantly increase the risk of surgery, and previous cardiac surgery.

\section{Those patients were divided into two groups:}

Group (I): Enrolled 30 patients, and were managed surgically at time of on pump coronary artery bypass grafting by repair (CABG + MVA).

Group (II): Enrolled 30 patients, and were managed by on pump coronary artery bypass grafting alone(CABG alone).

\section{Patients were subjected to the following:}

- Preoperative parameters: 1) History taking: A thorough and detailed history taken, as regards the age, sex, functional class according to New York Heart Association classification. 2) Clinical examination: A complete clinical general and local 
cardiological examination was performed. 3) Investigations:

- Laboratory investigations: 1) Complete blood count (CBC). 2) Liver function tests (total and direct bilirubin, liver enzymes "AST", "ALT", serum albumin, serum proteins, prothrombin time and concentration. 3) Kidney function tests (serum urea \& creatinine). d- Fasting blood sugar. 4) Serum electrolytes.

- Electrocardiogram (ECG), Radiological examination and Echocardiography, Coronary angiography.

Intra-operative procedures: 1) Anaesthetic technique. 2) Surgical technique.

Operative parameters: 1) Aortic cross clamp time (AXCT). 2) Total bypass time. 3) Total operation time. 4) Use of inotropic drugs. 5) Use of intra aortic balloon.

Post-operative evaluation of both groups: 1) Intensive care unit evaluation. 2) One week evaluation. 3) 3 and 6 months evaluation.

\section{Stastical Analysis:}

Results were expressed as mean of standard deviations (SD) or number (\%). Comparison between the two groups was performed using unpaired student $t$ test.
While comparison between preoperative and postoperative data within the same group was performed using paired student $t$ test. Categorical data were compared using Chi square test. The data were considered significant if $\mathrm{p}$ values were equal to or less than 0.05 . Statistical analysis was performed with the aid of the SPSS computer program (version 10 windows).

\section{RESULTS:}

In the period between July 2017 and June 2020, 60 patients with moderate ischaemic mitral regurgitation (IMR) divided in 2 equal groups underwent open heart surgery at Nasser Institute cariac surgery department and the Cardiac Surgery Department, faculty of medicine, Ain Shams university. Group (I) had both CABG surgery associated with MV repair, while, Group (II) underwent CABG surgery alone to assess whether revascularization alone is sufficient for managing those patients or revascularization is to be combined with mitral valve repair. The preoperative, operative, postoperative, and follow up data of both groups were studied.

Table 1. Demographic data of the two studied groups

\begin{tabular}{|c|c|c|c|c|c|c|}
\hline & \multicolumn{3}{|c|}{ Groups } & \multicolumn{2}{|c|}{ T-test and Chi-square } \\
\hline & & \multicolumn{2}{|c|}{ Group I } & Group II & T or $X^{2}$ & P-value \\
\hline & Mean \pm SD & $66.433=$ & 12.593 & $68.923 \pm 13.345$ & -0.743 & 0.460 \\
\hline \multirow{2}{*}{$\begin{array}{c}\text { Sex N } \\
(\%)\end{array}$} & Female & 10 & $(33.3 \%)$ & $(20.0 \%)$ & \multirow{2}{*}{1.375} & \multirow{2}{*}{0.241} \\
\hline & Male & 20 & $(66.7 \%)$ & $(80.0 \%)$ & & \\
\hline
\end{tabular}

Patients underwent a thorough clinical evaluation which included history taking, general and cardiac examination.

Table 2. Preoperative infarction in the studied groups

\begin{tabular}{|c|c|c|c|c|c|c|c|c|c|}
\hline & \multicolumn{4}{|c|}{ Groups } & \multirow{2}{*}{\multicolumn{2}{|c|}{ Total }} & \multirow{2}{*}{\multicolumn{2}{|c|}{ Chi-square }} \\
\hline & & \multicolumn{2}{|c|}{ Group I } & \multicolumn{2}{|c|}{ Group II } & & & & \\
\hline & & $\mathrm{N}$ & $\%$ & $\mathrm{~N}$ & $\%$ & $\mathrm{~N}$ & $\%$ & $X^{2}$ & P-value \\
\hline \multirow{3}{*}{ Infarction } & Negative & 9 & $30.0 \%$ & 7 & $23.3 \%$ & 16 & $26.7 \%$ & \multirow{3}{*}{0.085} & \multirow{3}{*}{0.770} \\
\hline & Positive & 21 & $70.0 \%$ & 23 & $76.7 \%$ & 44 & $73.3 \%$ & & \\
\hline & Total & 30 & $100.0 \%$ & 30 & $100.0 \%$ & 60 & $100.0 \%$ & & \\
\hline
\end{tabular}

Table 3. Risk factors in the two studied groups: 
Walaa Ahmed Saber, et al.,

\begin{tabular}{|c|c|c|c|c|c|c|c|c|c|}
\hline & & \multicolumn{4}{|c|}{ Groups } & \multirow{2}{*}{\multicolumn{2}{|c|}{ Total }} & \multirow{2}{*}{\multicolumn{2}{|c|}{ Chi-square }} \\
\hline & & \multicolumn{2}{|c|}{ Group I } & \multicolumn{2}{|c|}{ Group II } & & & & \\
\hline & & $\mathrm{N}$ & $\%$ & $\mathrm{~N}$ & $\%$ & $\mathrm{~N}$ & $\%$ & $\mathrm{X}^{2}$ & $\mathrm{P}$-value \\
\hline \multirow[b]{2}{*}{ DM } & Negative & 16 & $53.3 \%$ & 13 & $43.3 \%$ & 29 & $48.3 \%$ & \multirow{2}{*}{0.602} & \multirow[b]{2}{*}{0.438} \\
\hline & Positive & 14 & $46.7 \%$ & 17 & $56.7 \%$ & 31 & $51.7 \%$ & & \\
\hline \multirow{2}{*}{ Hypertension } & Negative & 10 & $33.3 \%$ & 9 & $30.0 \%$ & 19 & $31.7 \%$ & \multirow{2}{*}{0.077} & \multirow{2}{*}{0.781} \\
\hline & Positive & 20 & $66.7 \%$ & 21 & $70.0 \%$ & 41 & $68.3 \%$ & & \\
\hline \multirow{2}{*}{ Hyperlipidemia } & Negative & 7 & $23.3 \%$ & 8 & $26.7 \%$ & 15 & $25.0 \%$ & \multirow{2}{*}{0.089} & \multirow{2}{*}{0.766} \\
\hline & Positive & 23 & $76.7 \%$ & 22 & $73.3 \%$ & 45 & $75.0 \%$ & & \\
\hline \multirow{2}{*}{ Smoking } & Negative & 18 & $60.0 \%$ & 13 & $43.3 \%$ & 31 & $51.7 \%$ & \multirow{2}{*}{1.676} & \multirow{2}{*}{0.195} \\
\hline & Positive & 12 & $40.0 \%$ & 17 & $56.7 \%$ & 29 & $48.3 \%$ & & \\
\hline
\end{tabular}

Table 4. Preoperative NYHA Class Assessment

\begin{tabular}{|c|c|c|c|c|c|c|c|c|c|}
\hline & \multicolumn{4}{|c|}{ Groups } & \multirow{2}{*}{\multicolumn{2}{|c|}{ Total }} & \multirow{2}{*}{\multicolumn{2}{|c|}{ Chi-square }} \\
\hline & & \multicolumn{2}{|c|}{ Group I } & \multicolumn{2}{|c|}{ Group II } & & & & \\
\hline & & $\mathrm{N}$ & $\%$ & $\mathrm{~N}$ & $\%$ & $\mathrm{~N}$ & $\%$ & $\mathrm{X}^{2}$ & P-value \\
\hline \multirow{3}{*}{ NYHA } & II & 12 & $40.0 \%$ & 17 & $56.7 \%$ & 29 & $48.3 \%$ & \multirow{3}{*}{1.676} & \multirow{3}{*}{0.195} \\
\hline & III & 18 & $60.0 \%$ & 13 & $43.3 \%$ & 31 & $51.7 \%$ & & \\
\hline & Total & 30 & $100.0 \%$ & 30 & $100.0 \%$ & 60 & $100.0 \%$ & & \\
\hline
\end{tabular}

The preoperative echocardiographic data of both groups are mentioned. There was no statistically-significant difference between both groups.

Table 5. Preoperative Echocardiographic Data of both groups

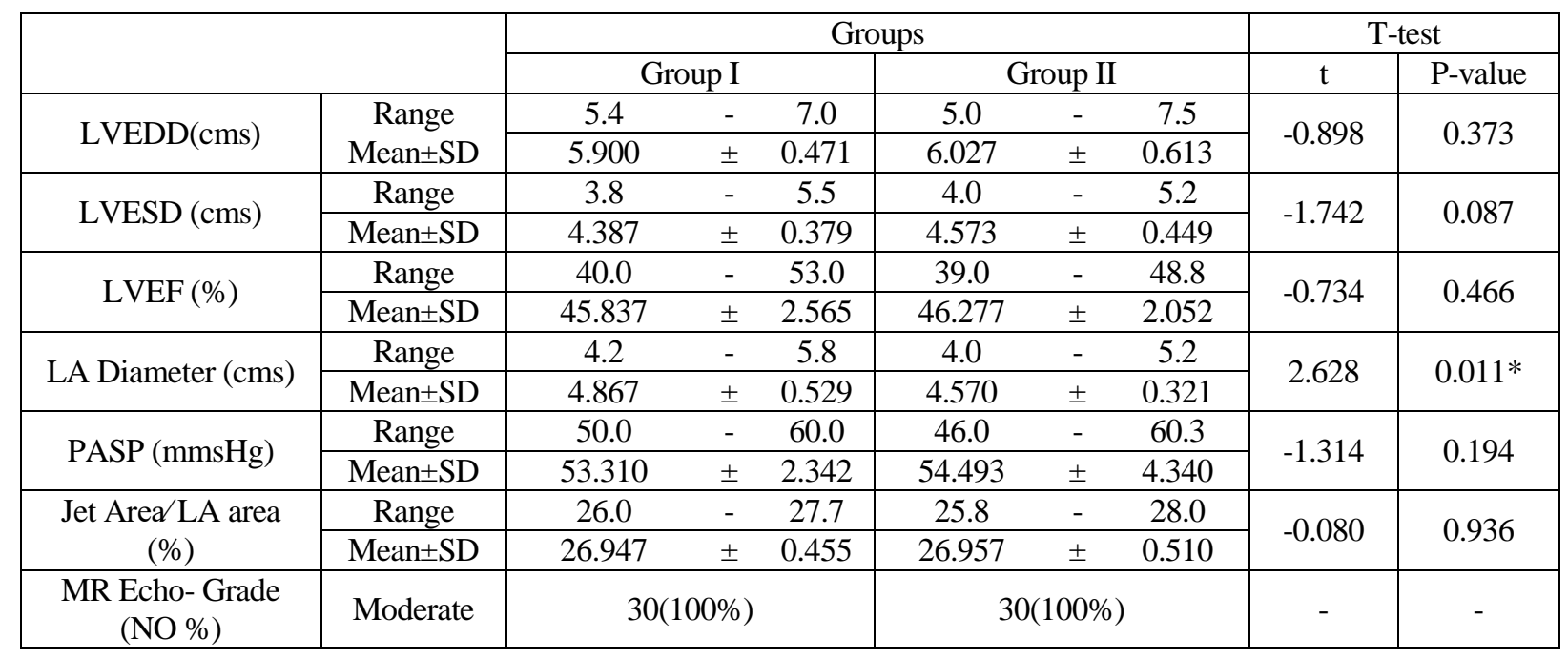

\section{DISCUSSION:}

Ischaemic mitral regurgitation (IMR) is a complication of coronary artery disease (CAD) with normal chordal and leaflet morphology. IMR is associated with increased mortality as well as risk of development of heart failure, regardless of the treatment employed. Approximately, one half of patients following a myocardial infarction develop IMR, while up to $17 \%$ develop moderate or severe IMR ${ }^{(10)}$.
Paucity of data contributes to the controversy surrounding the issue of optimal treatment for moderate IMR. Proponents advocating combined MV repair and coronary artery bypass grafting (CABG) emphasize that $40 \%$ of patients continue to have moderate or severe mitral regurgitation (MR) after isolated CABG and that persistent or progressive MR may lead to worse outcomes ${ }^{(\mathbf{1 1})}$.

It is, however, unclear whether the lower prevalence of MR following the combined procedure has any clinical benefit. Some studies suggested a functional benefit from concomitant 
MV surgery, while others found neither symptomatic nor survival benefit from the addition of MV surgery to $\mathrm{CABG}^{(\mathbf{1 2})}$.

Considering the lack of consensus on optimal treatment method for moderate IMR, we conducted the present study. It aims to determine whether a concomitant MV repair during CABG improves clinical outcome in moderate IMR patients.

In this study, we comparatively-studied the course of un-repaired moderate mitral regurgitation after CABG alone, versus CABG with repair, in order to assess the impact of un-repaired moderate ischemic mitral regurgitation on the immediate and early outcome of CAD patients undergoing standard CABG using CPB.

This study population encompassed $60 \mathrm{CAD}$ patients complicated by moderate IMR who underwent CABG with (group I, no 30) or without mitral valve repair (group II, no 30). The study was carried out between July 2017 and June 2020, in the department of cardiac surgery of Nasser institute and the department of cardiac surgery, faculty of medicine,Ain Shams university after obtaining the approval of the local ethical committee and a fully-informed written consent.

As regard functional status, The majority of patients in our study were in NYHA class II-III with overall mean NYHA class of $2.3 \pm 0.5$. In group I, 12 patients (40\%) had NYHA Class II dyspnoea; 18 patients $(60 \%)$ had NYHA class III $\&$ mean NYHA of $2.11 \pm 1.35$. In group II, 17 patients $(56 \%)$ and 13 patients $(43 \%)$ had classes II and III respectively \& mean NYHA class of 2.2 \pm 1.41 . Values were statistically- insignificant $(\mathrm{p}=$ 0.152 ).

Similar mean values of preoperative NYHA class (between II-III) were reported in the series by other studies like Bouchard et al. ${ }^{(\mathbf{1 3})}$ who reported mean NYHA of 2.3 in CABG+ MVr group\& 2.4 in $\mathrm{CABG}$ group $(\mathrm{P}=0.56)$.

Regarding previous $\mathbf{M I}$ in group (I) 21 (70\%) had previous MI compared to $23(76 \%)$ in group (II) with no statistical significant difference.

This percentage of patients who had positive history of previous MI was comparable to other studies by Bouchard et al. (13) where the percentages were $(75 \%)$ in $\mathrm{CABG}+\mathrm{MVr}$ group\& (72\%) in CABG group.
In this study group, we found no correlation between the preoperative LA diameter and the presence of moderate MR $(\mathrm{p}=0.235=\mathrm{NS})$. Although unexpected, this can be explained by the fact that the left atrium is exposed to the LV filling pressures through the open mitral orifice during diastole, the size of which should therefore be influenced by the same factors that determine the diastolic filling pressure of the left ventricle ${ }^{(\mathbf{1 4})}$.

Operative data analysis including total pump time and ischemic time revealed a significant difference when comparing the two groups. This significant difference in favour of group II was observed.

As regard to total pump time, group I showed a mean pump time of $123 \pm 8 \mathrm{~min}$, while it was $90.5 \pm 4.5 \mathrm{~min}$ in group II. When compared with other studies, results from Smith et al. ${ }^{(\mathbf{1 2})}$ also showed statistically significant difference between their two groups, the first study reported a median total pump time of $147 \mathrm{~min}$ and 84min for Repair group and $\mathrm{CABG}$ only group respectively; while the second study reported $163.1 \pm 54.9 \mathrm{~min}$ and $106.8 \pm 49.7 \mathrm{~min}$ for corresponding groups respectively.

While for cross clamp time, Group I showed ischemic time of $72.3 \pm 9.7 \mathrm{Min}$, and group II showed $474 \pm 10.4 \mathrm{~min}$. In the same fashion, Chan et al. ${ }^{(15)}$ reported a median of 95 and $51 \mathrm{~min}$, and Smith et al. (12) reported 117.2 \pm 35 .4and $74.7 \pm 36.7 \mathrm{~min}$ for their Repair group and CABG only group respectively.

Likewise, Wong et al. ${ }^{(16)}$ in their study of 251 patients having IMR including 31 patients who received concomitant mitral valve annuloplasty during $\mathrm{CABG}$, had no statistical difference between their two groups in the use of high support with the baseline mean EF of their patient's slightly less than ours. And, they had higher rates of IABP insertion, $6.4 \%$ and $2.3 \%$ in corresponding groups respectively. This difference might be attributed statistically to the large number of $(\mathrm{n}=251)$ patients and less LV functions included in their study.

The preoperative LVEF\% of $47.8 \%$ stepped up to $50.3 \%$ and 56.6

$\%$ in the early and late $\mathrm{PO}$ periods respectively. Postoperatively, IMR downgraded to mild, \& mean jet area\% decreased from preoperative value of $26.9 \%$ to $14 \%$ and $20 \%$ over 


\section{Walaa Ahmed Saber, et al.,}

the early and late PO periods (respectively). Fattouch et al. ${ }^{(17)}$ reported improvement in LVEF\% from baseline of $43 \pm 9$ to $45 \pm 7$ with no significant improvement of Mean MR grade which graded from from moderate to mild.

It is worth-mentioning that the differences between the two groups showed no statistical significance in the immediate PO period, and significance during the early and late PO periods. The adaptation to the increased in afterload after the return of mitral valve competency could explain the absence of LVEF improvement after annuloplasty. As the ventricle adapts and the volume overload recedes, LV function will start to improve by 6-12 months.

As was evident from the previous display of our study results, CABG alone did, to some extent, improve IMR over 6 months of follow- up. Although the overall postoperative clinical parameters demonstrated statistically-significant values in both groups, CABG combined with mitral repair achieved more improvement in the clinical follow-up parameters (EF \%, Jet area \& MR echo-grade \& mean NYHA class) when compared to preoperative patient condition.

Finally, the principle finding of this study is that intervention on the mitral valve likely improved short term survival benefit over CABG alone. We conclude that there is good evidence to suggest that moderate mitral regurgitation in patients undergoing isolated CABG adversely NYHA functional class and mitral regurgitation does not reliably improve after CABG alone. We have to consider that Ischemic Mitral Regurgitation has two major contributing variables which may vary widely, the severity of MR and the LV dysfunction. Unfortunately, the evidence to support mitral valve repair at the time of CABG to improve long-term survival is still weak. On balance, patients with moderate ischaemic mitral regurgitation having $\mathrm{CABG}$ should have mitral repair at the same time, although the evidence to support this is weaker than one might like. A very important question should be raised here, which is: How can we evaluate the outcome while it might persist or recur using current treatment options?! The challenge is to better identify patients for whom each surgical strategy is more beneficial and to develop more effective treatment for IMR.

\section{Conclusion:}

After assessing all our study results, we came up to the following conclusions: Our primary end point was achieved, and the efficacy of adding MVR to CABG is well demonstrated by the improvement of NYHA functional class and LVEF over the early (3 months) \& late (6 months) postoperative follow-up periods. Performing CABG combined with a mitral repair procedure dose not add any serious burden to the operative risk nor does it affect the immediate and early outcomes in this patient subset. Moderate ischemic MR progresses to more severe grades in only a minority of patients (4\%) in the early follow-up period following Combined CABG + MV repair compared to a higher incidence (8\%) in patients submitted to $\mathrm{CABG}$ only. Presence of more residual IMR in the CABG (alone) group did not adversely-affect the immediate or early outcome of the operation by causing more morbidity complications especially when controlled by optimal medical treatment with diuretics-Bblockers-ACE inhibitors.

\section{REFERENCES:}

1. Goland S, Czer LS, Siegel RJ, DeRobertis MA, Mirocha J, Zivari K, Kass RM, Raissi S, Fontana G, Cheng W, Trento A. Coronary revascularization alone or with mitral valve repair: outcomes in patients with moderate ischemic mitral regurgitation. Texas Heart Institute Journal. 2009; 36(5):416. Cited from (Gulack BC, Englum BR, Castleberry AW, Daneshmand MA, Smith PK, Perrault LP. Repair or observe moderate ischemic mitral regurgitation during coronary artery bypass grafting? Prospective randomized multicenter data. Annals of Cardiothoracic Surgery. 2017; 4(3):266-272.

2. Enriquez-Sarano M, Schaff HV, Frye RL. Mitral regurgitation: what causes the leakage is fundamental to the outcome of valve repair. Circulation 2007;108(3):253-6.Cited from (Michele De Bonis, Steven F. Bolling. Mitral valve surgery: wait and see vs. early operation. European Heart Journal (2016) 34, 13-19)

3. Grigioni F, Enriquez-Sarano M, Zehr KJ, Bailey KR, Tajik AJ. Ischemic mitral regurgitation: long-term outcome and 
prognostic implications with quantitative Doppler assessment. Circulation 2004;103(13):1759-64. Cited from (Gulack BC, Englum BR, Castleberry AW, Daneshmand MA, Smith PK, Perrault LP. Repair or observe moderate ischemic mitral regurgitation during coronary artery bypass grafting? Prospective randomized multicenter data.Annals of Cardiothoracic Surgery. 2017;4(3):266-272.).

4. Levine RA, Schwammenthal E. Ischemic mitral regurgitation on the threshold of a solution: from paradoxes to unifying concepts. Circulation 2008;112(5):74558.Cited from (Ahmad Masri, Shadi Al Halabi, Ahmadreza Karimianpour, Alan Marc Gillinov, Peyman Naji, Joseph F. Sabik, Tomislav Mihaljevic, Lars G. Svensson, Luis Leonardo Rodriguez, Brian P. Griffin, and Milind Y. Desai. Impact of additive mitral valve surgery to coronary artery bypass grafting on mortality in patients with coronary artery disease and ischaemic mitral regurgitation: a systematic review and meta-analysis of randomized trials and observational studies European Heart Journal - Quality of Care and Clinical Outcomes (2018) 2, 33-44).

5. Hung J, Papakostas L, Tahta SA, Hardy BG, Bollen BA, Duran CM, Levine RA. Mechanism of recurrent ischemic mitral regurgitation after annuloplasty: continued LV remodeling as a moving target. Circulation 2007;110(11 Suppl 1): II85-90.

6. Akins CW, Hilgenberg AD, Buckley MJ, Vlahakes GJ, Torchiana DF, Daggett WM, Austen WG. Mitral valve reconstruction versus replacement for degenerative or ischemic mitral regurgitation. Ann Thorac Surg 1998;58(3):668 76.cited from (Mick SL, Keshavamurthy S, Gillinov AM. Mitral valve repair versus replacement.Ann Cardiothorac Surg 2017;4(3)230-237.)

7. Duarte IG, Shen Y, MacDonald MJ, Jones EL, Craver JM, Guyton RA. Treatment of moderate mitral regurgitation and coronary disease by coronary bypass alone: late results. Ann Thorac Surg 2002;68(2):426-30.

8. Czer LS, Maurer G, Bolger AF, DeRobertis M, Chaux A, Matloff JM. Revascularization alone or combined with suture annuloplasty for ischemic mitral regurgitation. Evaluation by color Doppler echocardiography. Tex Heart Inst J 1999;23 (4):270-8.

9. Di Mauro M, Di Giammarco G, Vitolla G, Contini M, Iaco AL, Bivona A, et al. Impact of no-to-moderate mitral regurgitation on late results after isolated coronary artery bypass grafting in patients with ischemic cardiomyopathy. Ann Thorac Surg 2009;81(6):2128- 34.

10. Castleberry AW, Williams JB, Daneshmand MA, Honeycutt E, Shaw LK, Samad Z et al. Surgical revascularization is associated with maximal survival in patients with ischemic mitral regurgitation: a 20-year experience.Circulation 2016;129:2547-56.

11. Zhang H, Liu Y, Qiu S, Liang W, Jiang L. Short-Term and Long- Term Survival After Revascularization with or without Mitral Valve Surgery of Patients with Ischemic Mitral Valve Regurgitation: A MetaAnalysis. Medical Science Monitor: International Medical Journal of Experimental and Clinical Research. 2016;21:3784-3791.

12. Smith PK, Puskas JD, Ascheim DD, Voisine P, Gelijns AC, Moskowitz AJ et al. Surgical treatment of moderate ischemic mitral regurgitation. N Engl J Med 2014;371:217888.

13. Bouchard D, Jensen H, Carrier M, Demers P, Pellerin M, Perrault LP et al. Effect of systematic downsizing rigid ring annuloplasty in patients with $10 \mathrm{~T}$. Kopjar et al. / European Journal of Cardio-Thoracic Surgery moderate ischemic mitral regurgitation. J Thorac Cardiovasc Surg 2016; 147:14.

14. Magne J, Pibarot P, Dagenais F, Hachicha Z, Dumesnil JG, Se'ne'chal M. Preoperative posterior leaflet angle accurately predicts outcome after restrictive mitral valve annuloplasty for ischemic mitral regurgitation. Circulation 2007; 115:78291.

15. Chan KMJ, Punjabi PP, Flather M, Wage R, Symmonds K, Roussin I et al. Coronary artery bypass surgery with or without mitral 
Walaa Ahmed Saber, et al.,

valve annuloplasty in moderate functional ischemic mitral regurgitation: final results of the Randomized Ischemic Mitral Evaluation (RIME) trial. Circulation 2015; 126: $2502-$ 10.

16. Wong DR, Agnihotri AK, Hung JW, Vlahakes GJ, Akins CW, Hilgenberg AD et al. Long-term survival after surgical revascularization for moderate ischemic mitral regurgitation. Ann Thorac Surg 2008; 80:570-7.

17. Fattouch K, Guccione F, Sampognaro R, Panzarella G, Corrado E, Navarra E et al. POINT: efficacy of adding mitral valve restrictive annuloplasty to coronary artery bypass grafting in patients with moderate ischemic mitral valve regurgitation: a randomized trial. J Thorac Cardiovasc Surg 2012; 138:278-85. 


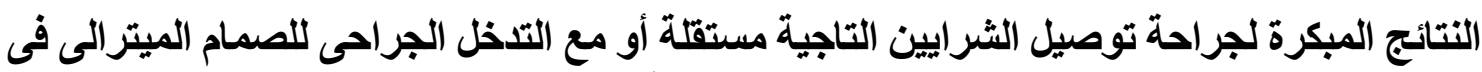

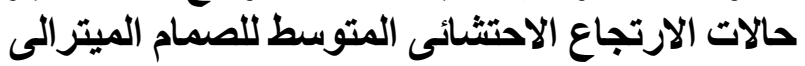

ولاء أحمد صابر، محمد محمد الفقى، أسامة عباس عبدالحميد، عحمد نبيل عبدالجواد، السيد منصور السيد حرى

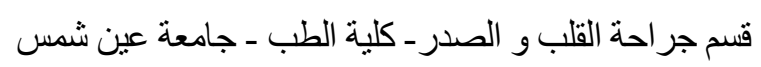

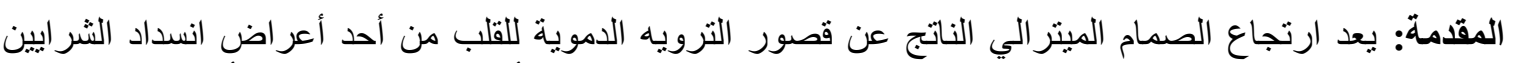

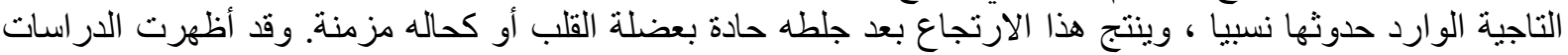

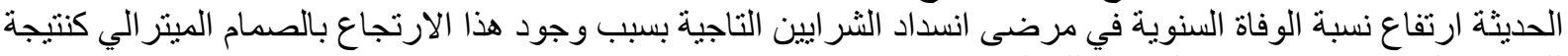
للقصور الدموي مع الارتباط الوثيق لتلاك النسبة بزيادة درجة النئة الارتجاع.

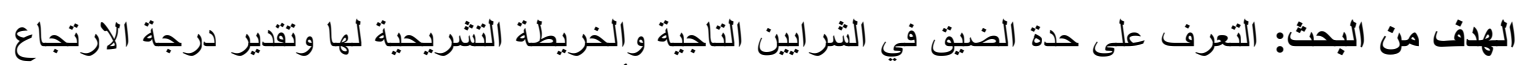

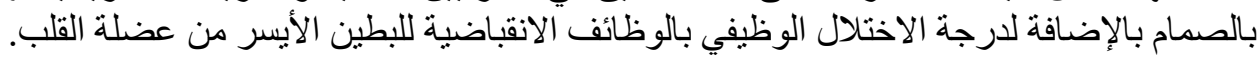

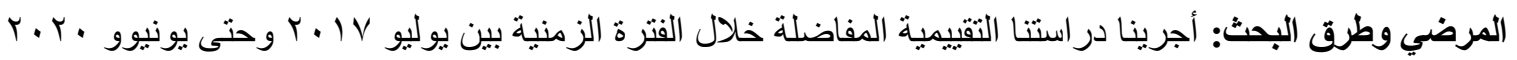

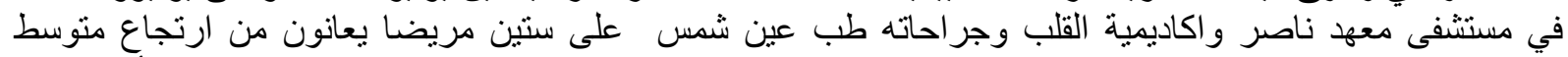

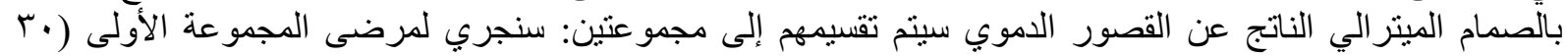

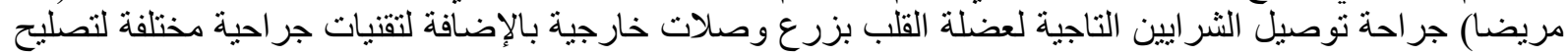

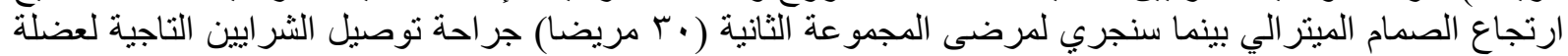
القلب بزرع وصنات خارجية فقط.

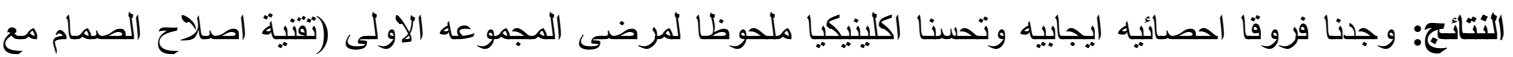

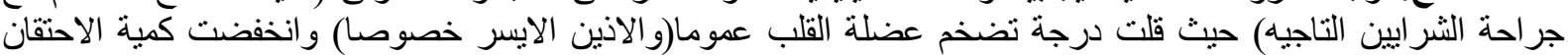

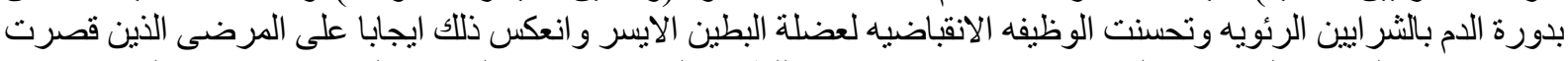

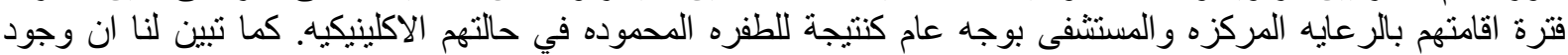

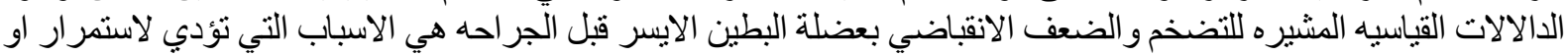

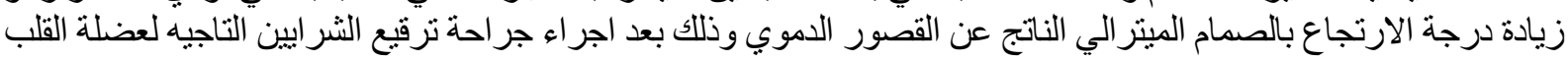
بزرع وصلات خارجيه.

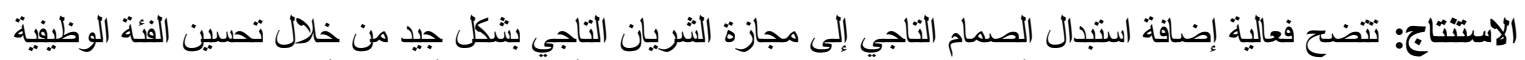

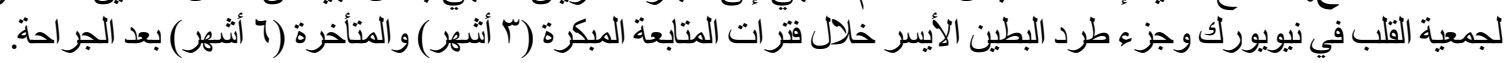

